\title{
CAMINOS GANADEROS MURCIANOS DURANTE LA BAJA EDAD MEDIA. RECONSTRUCCION DOCUMENTAL
}

\author{
M. a de los Llanos Martínez Carrillo \\ Universidad de Murcia
}

La trascendencia de las rutas ganaderas como elementos fundamentales de la comunicación humana, más allá de sus estrictos planteamientos materiales de base ${ }^{1}$, está generalmente reconocida, siendo el objeto de este trabajo la reconstrucción unitaria de las que atravesaban el término concejil murciano y su conexión con las grandes rutas castellanas y aragonesas.

Torres Fontes ha subrayado el hecho de que el concejo murciano se opusiese continuadamente a que la "vereda» principal o sus variantes utilizadas en el reino murciano por los ganados mesteños, pudiesen ser consideradas como continuación de la cañada de Cuenca, al estar trazadas sobre tierras provenientes de los heredamientos de sus vecinos ${ }^{2}$. Durante la baja edad media, vereda era sinónimo de la tercera categoría en anchura de caminos ganaderos, equivalente a unas 25 varas castellanas, y hasta hoy mantiene su primitivo significado de "sendero, trocha, carril, atajo» ${ }^{3}$; en

${ }^{1}$ Fundamental es la valoración cartográfica en J. Bishro Sesenta años despues: La Mesta de Julius Klein a la luz de la investigación subsiguiente, "Historia. Instituciones. Documentos», 8, 1981, y la cultural de P. GARCí MARTín, El patrimonio cultural de las cañadas reales, Junta de Castilla-León, Valladolid, 1990.

2 J. TORRES FONTES, Notas para la bistoria de la ganadería murciana en la edad media, "Miscelánea Medieval Murciana», XII (en adelante MMM), p. 164. Continuación de la cañada de Cuenca era en el siglo XVII, G LEMEUNIER, Les extremeños, ceux qui viennent de loin. Contribution a l'étude de la transhumance ovine dans l'est castillan (XVI-XIX s.), "Mélanges de la Casa de Velázquez», XIII, 1977, «carte» 1 a continuación de página 340. El más reciente trabajo sobre vías pecuarias de la región se basa en una bibliografía de carácter general con aplicaciones al siglo XVIII, C. Flores Casanova y C. Flores Flores, Vias pecuarias de la región de Murcia. Los caminos de la Región de Murcia. Función bistórica y rentabilidad socioeconómica, Consejería de Política Territorial y Obras Públicas - Caja de Ahorros del Mediterráneo, 1989, pp. 275-288.

3 A. Llorente Maldonado de Guevara, Las denominaciones del "camino de ganado» en 
una palabra, era un camino secundario frente al camino principal que era la "cañada", denominación que no aparece en la documentación murciana de los siglos XIII-XV, en contraposición a la afirmación de Klein de que la cañada de Cuenca llegaba "hasta las llanuras murcianas " ${ }^{4}$.

Esta valoración del camino ganadero como vereda y no como cañada hay que relacionarla con la existencia de una fuerte autonomía jurisdiccional en los ganados locales y el concejo de Murcia, que afectaba necesariamente al gobierno de los pastos y sus vías de comunicación, constituyendo un fenómeno que puede ser considerado de "mesta local», tal como ha sido intuido por Bishko, y cuya primera concreción legal fue la aprobación de las ordenanzas de ganaderos murcianos de $1383^{5}$. Esta situación explica toda la evolución del sistema ganadero murciano y el que una cartografía de las Cañadas Reales, como fue el mapa de 1902 de Ibáñez e Ibáñez de Ibero ${ }^{6}$ dejase absolutamente en blanco el territorio murciano, situando la cañada de Cuenca en su travesía manchega hasta llegar a Sierra Morena.

El trayecto más deducible de la "vereda mayor" que cruzaba el territorio murciano y vertebraba el regadío del Segura, es el comprendido entre Abanilla y el Puerto de Cartagena, reconstruido merced a los retazos documentales que hacen referencia a sus casi infinitos amojonamientos, en uno de los cuales realizado en 1496 se puntualizaba que se haría «...desde que Juan Cabrero dio donde salle la vereda del termino de la villa de Havanilla y entra en el termino desta çibdad hasta el puerto de Cartagena...» ${ }^{7}$. El contrato de arrendamiento de las carnicerías de 1436 señalaba a los ganados que les iban a aprovisionar ese año tres rutas de entrada y salida en el «monte»: la Puerta de Molina hacia San Cristóbal, el camino de Cartagena

las provincias de Zamora, Salamanca y Avila, *Homenaje al profesor Luis Rubio» II, Universidad de Murcia, 1987-1989, p. 804.

4 J. Klein, La Mesta. Estudio de la historia económica española. 1273-1836, Alianza, 1979, p. 33 y mapa de pp. 38-39.

5 J. Bishko, Sesenta años después..., p. 33; M.' Ll. Martinez Carrillo, La ganadería lanar y las ordenanzas de ganaderos murcianos de 1383, MMM, IX, pp. 121-152.

6 Incluido en Descripción de las Cañadas Reales de León, Segovia, Soria y ramales de la de Cuenca y del valle de La Alcudia, El Museo Universal, Madrid, 1984. Posteriormente han sido hitos cartográficos importantes A. Fribourg, La transhumance en Espagne, "Annales de géographie», XIX, 1910, pp. 231-244; J. DANTÍN CERECEDA, Cañadas ganaderas españolas, "Congresso do mundo portugues. Publicaçoes", Lisboa, 1940, pp. 682-696, y C. SÁz Rodriguez, P. Garcia Martin y J. Garcia Saiz, Las rutas de La Mesta, "Cauce 2000", 10, 1986.

7 Archivo Municipal de Murcia, Acta Capitular (en adelante AMM y AC, respectivamente) 1496, f. 66 (29-X-1496). El corregidor Juan Cabrero gestionó la concordia entre ganaderos que dio como resultado un amojonamiento de la vereda que es el punto de referencia. A.C. 1487, f. 136 rev. (5-XII-1487), J. TORRES FONTES, Notas para la bistoria..., p. 165. 
y el camino de Algezares ${ }^{\gamma}$, las dos primeras coincidentes con dos tramos de la vereda y, la tercera, camino alternativo del segundo en circunstancias muy concretas.

Pero es el arrendamiento de las penas de la dehesa de 1454 el documento que marca más claramente cuales eran los ejes principales de entrada y salida de ganados en el área de la dehesa y huerta, procedentes de tierras del Sistema Ibérico conquense y Chinchilla; al más largo, a través de Abanilla, desde el Puerto de Zacacho al de Cartagena, se le concedían cuatro días y cuatro noches para recorrerlo a través de las líneas de contacto entre la dehesa y la huerta; y el más corto, con tres días y tres noches para hacer su recorrido a la entrada y otros tantos a la salida, iba desde el Portichuelo de Molina al de Cartagena donde ambos confluían", ésta última vereda ampliamente coincidente con el camino castellano.

1. Por término de Abanilla entraban ganados desde la "cañada de los serranos" conquenses, que continuaban por el Puerto de Zacacho y llegaban al puente del azud, "...vereda por do vienen los ganados de la parte de Hauanilla fasta el açud...", procedentes de las tierras de Jorquera en la cuenca del Júcar y los altiplanos de Yecla y Pinoso, desde la que un ramal divergía hacia tierras alicantinas ${ }^{10}$; vía reiteradamente amojonada, lo cual evidencia su uso así como su destrucción intencionada por los propietarios de las tierras adyacentes ${ }^{11}$. Desde Abanilla, a continuación atravesaba Fortuna y el Campo de la Matanza ${ }^{12}$, parte integrante de la dehesa concejil; más adelante la vereda pasaba por el puerto de Zacacho ${ }^{13}$, para continuar «...ençima de la Cabeza del Trigo a la parte de Santomera...», donde había una balsa de utilización ganadera ${ }^{14}$ que estaba al cuidado del obrero de las balsas y se limpiaba y mantenía, como todas las del Campo de Cartagena utilizadas por los ganados mesteños, con el fondo recaudado de ellos, 10

${ }^{8} A C$ 1435, f. 63 rev. (24-III-1436).

9 AC 1454, f. 46 rev. (15-XII-1454).

10 AC 1436, f. 38 rev. (10-XI-1436) y 1500, f. 73 rev. (31-X-1500). J. TORRES FonTes, El señorio de Abanilla, Academia Alfonso X el Sabio, Murcia, 1982. F.M. MarTínez. FronCE, Alicante: una Extremadura mesteña, "Studia Historica. In Honorem Vicente Martínez Morellá», Excma. Diputación Provincial de Alicante, 1985, pp. 254-255.

$"$ "AC 1439, f. 24 rev. (22-IX-1439 y 1498, f. 110 rev. 23-III-1499).

12 AC 1382, f. 118 (11-II-1383), M." C. Veas Arteseros, Notas para el estudio de la ganadería del Marquesado de Villena. "Congreso de Historia del Señorío de Villena", Albacete, 1987, p. 421 . En 1486 se registra el permiso de estancia en el Campo de la Matanza de 600 cabezas de Gonzalo López, vecino de Huélamo, pagando 250 reales y renunciando así a llegar hasta el Campo de Cartagena, $A C$ 1486, f. 69 (2-I-1487).

$13 A C-1454$, f. 46 rev. (15-XII-1454).

14 AC-1468, f. $42(1468-\mathrm{X}-22)$ y 1489, f. 85 (24-XI-1489). 
mrs. por cada millar de ovejas, que tenía esta finalidad, lo que resulta prueba evidente de su utilización por estos ganados en ruta.

Desde Santomera, la vereda llegaba por la "costera" norte hasta San Cristóbal y desde allí a las inmediaciones de la ciudad en la Puerta de Molina $^{15} \mathrm{o}$, más generalmente, al puente ganadero construido en la cabecera del azud.

2. Desde las tierras de La Mancha los ganados entraban en el reino de Murcia haciendo etapas desde La Mancha albacetense, a través de Las Peñas (de San Pedro), Tobarra, Minateda y Calasparra ${ }^{16}$, siguiendo una ruta similar y paralela a la que llevaban la cañada procedente de Chinchilla y el camino real de Castilla, conectando ambos ramales a la altura de Tobarra, desde donde unificados penetraban en el territorio del Reino de Murcia ${ }^{17}$; sus indicios documentales son menores respecto al trayecto anterior, porque afectaba menos a los lindes de las tierras cultivadas, sobre todo las de regadío. Esta vereda de procedencia manchega se unía a través de un paso fluvial, posiblemente en las inmediaciones de Los Almadenes, con la que venía de las tierras montañosas de Moratalla y Caravaca a través de Mula, constituyendo una conexión con tierras, pastos y jurisdicciones de Alcaraz y la Orden de Santiago en los pastos de las tierras de Segura y Cazorla, conforme la frontera granadina fue retrocediendo y los pastos de Huéscar y Cazorla fueron más utilizables, en detrimento de los de Alcaraz, en los que en los finales del siglo Xv la presencia de ganados murcianos debía de ser mínima ${ }^{18}$. Más adelante esta ruta manchega conectaba con la de origen conquense por Jumilla y el Puerto de la Losilla hasta su entrada por el Portichuelo de Molina; esta ruta no se hace más notoria en los documentos, entre otras razones, por las exigencias fiscales de los alcaides de la villa fajardista de Molina ${ }^{19}$.

3. Todas estas rutas se unificaban para cruzar la debesa concejil, «...pasauan forçadamente por la uereda acostumbrada que es en la dehesa mayor de la dicha çibdad...» y por ende la huerta a la que ésta rodeaba, como prueba sistemáticamente la serie de problemas surgidos entre rabada-

is $A C-1435$, f. 63 rev. (24-III-1436).

${ }^{16} A C-1382$, f. 130 a 132 rev. (23-II-1383), M." C. VeAs Arteseros, Notas..., ps. 421 422. y a.c. 1438 , f. 86 rev. (9-VI-1439) y 1486, f. 44 (26-IX-1486).

${ }_{17}$ AC 1477, f. 119 rev. (17-III-1478), J. TORRES FonTES, Puerto de La Losilla, portazgo, torre $y$ arancel, «MMM», IX, 1982, p. 60.

${ }_{18}$ AC 1382, f. 118 rev. (11-II-1383) y 1471, f. 37 (28-IX-1471). M.' LI. MARTínEZ CARrillo, Revolución urbana y autoridad monárquica en Murcia durante la baja edad media (1395-1420), Universidad de Murcia, Academia Alfonso X el Sabio, 1980, p. 258. I. Garcin Dinz, Agricultura, ganaderia y bosque. La explotación econbmica de la Tierra de Alcaraz (1475-1530), Instituto de Estudios Albacetenses, 1987, p. 66.

19 AC 1454, f. 96 rev. (15-XII-1454) y 1475, f. 52 (26-IX-1475). 





nes y pastores con los hombres de los arrendadores municipales que los penaban ${ }^{20}$, en unos casos y, en otros, con agricultores que estrechaban la vereda labrándola o que eran víctimas del paso del ganado por sus tierras ${ }^{21}$.

Así, mientras eran los ganaderos mesteños quienes tenían que costear la vereda a través de un arrendador que cobraba las multas ${ }^{22}$, el concejo se responsabilizaba de la colocación de los mojones que la señalizaban «...con cabirones altos e con hachos de atocha...", en un principio con los fondos destinados a la limpieza de los pozos y balsas del campo y posteriormente con el cobro específico de 120 inrs. por millar de cabezas castellanas impuesto por el concejo durante años ${ }^{23}$ y que los ganaderos no admitieron hasta que los Reyes Católicos impusieron una «composición» o «capitulación» a ambas partes en virtud de la cual los ganaderos pagarían, pero el concejo se avenía a que el tiempo de paso fuese más largo ${ }^{24}$; en dicho acuerdo los ganaderos veían también renocido su derecho a indicar, junto con el concejo, donde debían estar los mojones, aunque no a levantarlos y, desde entonces, el cobro de los derecho de la vereda se hizo más estricto, exigiéndoles fianzas a su llegada ${ }^{25}$.

Era la vereda fundamental la que cruzaba la dehesa por su punto más estrecho, junto al azud mayor del rio Segura; la expresión «...la vereda de la dehesa..." ${ }^{26}$ se repite insistentemente en los documentos, lo cual no excluye la existencia de otras complementarias de ésta, ni el que los ganados mesteños entrasen y saliesen del Campo de Cartagena bordeando la dehesa, como ocurrió con los de Juan Ruiz de Yeste y Pedro Álvarez de Orihuela, que en 1439 quedaron excluidos del pago del derecho correspondiente «...por quanto non entraron por la dehesa desta çibdad con sus ganados en el Campo de Cartagena.... ${ }^{27}$.

${ }^{20}$ AC 1425, f. 40 rev. (3-XI-1425) y 1426, f. 74 rev. (23-III-1426). La delimitación de la dehesa en M. ${ }^{2}$ LI. MARTINEz CARRILLO, La ganadería lanar y las ordenanzas de ganaderos murcianos de 1383, "MMM", IX, 1982, p. 127.

21 AC 1462, f. 62 rev. (16-VI-1463).

22 AC 1476, f. 66 rev. (10-XII-1475); 1486, f. 105 (21-IV-1487); 1495, f. 70 rev. (10-XI-1495); 1497, f. 10 (8-VII-1497) y 1498, f. 84 (11-XII-1498).

${ }^{23}$ AC 1413, f. 60 (23-IX-1413); 1444, f. 23 (18-VIII-1444) y 1487, f. 56 (13-XI1487). M." Ll. Martinez Carrillo, Población y término de Cartagena en la baja edad media, "I Concurso de Historia de Cartagena "Federico Casal"", pp. 143-206, Ayuntamiento de Cartagena 1986.

${ }_{24}$ AC 1488, f. 10 rev. (19-VII-1488); Murcia, 1488-VII-22), Cartulario 1484-1495, f. 5, J. TORRes Fontes, Estampas de la vida en Murcia en el reinado de los Reyes Católicos, Academia Alfonso X el Sabio, Murcia, 1984, p. 311 y Notas para la bistoria de la ganaderí..., p. 164.

25 AC 1488, f. 47 (13-IX-1488) y 85 rev. (8-XI-1488).

${ }^{26}$ AC 1487, f. 100 (8-III-1488).

${ }^{27}$ AC 1438, f. 61 rev. (17-III-1439). 
4. El puente del azud sobre el Segura era un eslabón clave en el cruce de la dehesa por la vereda ganadera; existía desde 1271, construido por acuerdo concertado entre Domingo Bru y siete alcaldes de la Mesta de tierras de Cuenca y Albacete; el acuerdo, refrendado por un privilegio de Alfonso X, proyectaba su construcción en el tramo del Segura comprendido entre Molina y Alcantarilla, con posibilidades de explotación para Domingo Bru, de modo que fuera el único punto de cruce del río entre Calasparra y Orihuela. A cambio de su mantenimiento, Domingo Bru y sus herederos cobrarían una cabeza de ganado «...de las buenas...." ${ }^{28}$ por cada mil que utilizasen el puente. Definitivamente fue construido entre el azud mayor y Alcantarilla y en 1380, Juan I confirmaba las condiciones de su explotación a Fernando Oller que lo había comprado, presumiblemente a los herederos de Domingo Bru, cuyo nombre continuó llevando el puente.

En manos del regidor Fernando Oller y su hijo Andrés Fernández Oller, alguacil mayor y alcalde de la huerta ${ }^{29}$, estuvo el puente hasta 1424 ; incluso parece que no era este puente del azud el único paso ganadero sobre el rio que tenía Andrés Fernández Oller, pues en 1415 denunciaba que, junto a otros dos puentes que tenía, también de obra, próximos al azud y todos ellos ganaderos, fue arrastrado por una riada, de manera que para su reconstrucción cedió al concejo la mitad de los derechos de peaje, a cambio de un permiso temporal de paso de los ganados por el puente mayor de la ciudad $^{30}$, puentes que no eran sino una parte de sus amplios intereses ganaderos, demostrados también como arrendador de la dehesa mayor en $1412^{31}$.

En 1418, Andrés Fernández Oller comunicaba al concejo que lo había heredado de su padre y pedía un permiso, que obtuvo, para hacer una casa junto al puente, que calculaba situada a una legua de la ciudad ${ }^{32}$. Las noticias acerca de Andrés Fernández Oller son escasas, de tal manera que la razón por la que en 1424 se presentaba una carta real ante el concejo, otorgando a Alonso Fajardo, hijo de Juan Fajardo, las escribanías de las prime-

${ }^{28}$ Murcia, 1271 -II-18 y 1271 -VIII-27 y Soria, 1380-IX-20, insertos en una confirmación de Juan II de 1440, Cartulario 1478-1488, f. 207. J. TORres FonTes, Documentos de Alfonso X, "Coleccción de Documentos para la Historia del Reino de Murcia» (CODOM), I, Academia Alfonso X El Sabio, Murcia, 1963, documento XLVI. R. Serra Ruiz publicó el documento e hizo el estudio jurídico del mismo en 1961, sobre la base historiográfica de Cascales, Merino Alvárez, Valls Taberner y Torres Fontes, en El reino de Murcia y el Honrado Consejo de la Mesta (A propósito de un documento confirmado por Alfonso X, año 1271), "Estudios de Historia de Murcia», Academia Alfonso X El Sabio, Murcia, pp. 9-42.

29 M. ${ }^{2}$ Ll. Martínez Carrillo, Revolución urbana...., pp. 104, 178 y 239.

${ }^{30}$ AC 1415 , f. 87 rev. (12-XI-1415).

${ }^{31}$ AC 1412, f. 60 (29-XI-12).

${ }^{32}$ AC 1417 , f. 47 rev. (18-III-1418). 
ras y segundas alzadas de la ciudad y el derecho que Andrés Fernández Oller «...leuaua de la puente del azud...." ${ }^{33}$, no era otra que los alineamientos en favor de uno u otro de los Infantes de Aragón y sus aliados los Fajardo murcianos, por los cuales Andrés Fernández Oller o sus sucesores cayeron en desgracia.

En 1437 sus nuevos propietarios eran Isabel Gómez de Dávalos, casada con el caballero Juan de Avellaneda, y el también caballero Gonzalo Rodríguez de Avilés, que en aquella fecha hicieron un nuevo acuerdo con tres ganaderos albacetenses, dos chinchillanos y un conquense, en nombre de todos los que acudían al Campo de Cartagena, por el que se comprometían a remediar los retrasos que se producían en la marcha de los rebaños y las multas que recibían por entrar en la dehesa murciana indebidamente cada vez que las avenidas de agua se llevaban el endeble puente; en el plazo de un año a partir de San Miguel, se comprometían a sustituir a su costa los pilares de madera por otros de "...cal y canto..." de mayor altura, y a ensancharlo para que el paso de los ganados fuera más seguro y fluido; a su vez los ganaderos se comprometían a pagar en el futuro «...otra res por millar, asy que ayades e lleuedes por el dicho derecho del paso de la dicha puente agora et de aqui adelante, dos reses por cada millar, de las mejores que no sean de aquellas que se saluan.... ${ }^{34}$.

Ocho años más tarde, en 1445, Isabel Gómez de Dávalos demostraba en la corte que el puente, su derecho de paso y todos sus anexos le pertenecían exclusivamente por derecho de herencia de Andrés Fernández Oller. El valor de la rentas que el puente proporcionaba era tan considerable que fue la causa de la aparición de problemas en torno a aquella herencia, de tal modo que su resolución se planteó en la corte, donde Isabel Gómez de Dávalos solicitó y obtuvo, después de demostrar que era la única propietaria, un privilegio rodado de Juan II reconociéndole sus derechos en 1446.

Lo cierto es que el proceso abierto en la corte desde 1437 se planteó para recuperar una herencia y los derechos que habían quedado interrumpidos en 1424, y que Isabel Gómez de Dávalos y Juan de Avellaneda tenían "una casa» en el azud 35 , lo cual es indicativo de que el puente ganadero formaba parte de un patrimonio de tierras y jurisdicciones estratégicamente situadas, cuyo principal valor era precisamente su posición. En 1439 el

33 AC 1424, f. 48 rev. (14-XI-1424), la dependencia de los Oller respecto a Alfonso Yáñez Fajardo, integrándose en el entramado de su clientelismo conectado a los Moncada, se ve clara en el matrimonio de Andrés Fernández Oller e Inés de Moncada, que ya era viuda en 1426, AC 1425, f. 87 rev. (30-IV-1426); M.' Ll. Martinez Carrillo, Manueles y Fajardos. La crisis bajomedieval en Murcia, Academia Alfonso X El Sabio, Murcia, 1985, p. 89. 206.

${ }^{34}$ Murcia, 1437-III-26 y Tudela de Duero, 1466-VIII-12, Cartulario 1478-1488, f.

3s AC 1445, f. 43 rev. (11-XII-1445). 
puente había sido reconstruido por Avellaneda "...e auia fecho mucha costa...", cuando una nueva avenida lo derribó ${ }^{36}$ y en sus manos y en las de su viuda estuvo hasta mediados de siglo.

En noviembre de 1454, el concejo acusaba el hecho frecuente de que los ganados «...por Pedro Manuel no tener puente...», cruzaban por el puente de la ciudad, con los consiguientes desperfectos de cosechas y caminos, por lo que exigieron que, a la salida del campo, el puente estuviera reconstruido por él "...pues lieva el derecho della..."; desde entonces los documentos recogen tanto el incumplimiento de Pedro Manuel y después su viuda Beatriz de Avellaneda ${ }^{37}$, de tener el puente practicable, como el hecho de que labraban tierras en torno al azud y que en su casa se guardaban las herramientas de la obra, unas veces anotándose que había secanos en la heredad, otras que se utilizaba para riego el agua de la Alquibla, otras que la atochada de la Aljufia se hacía en la propia heredad y viéndose en peligro por el paso de los ganados por el puente, y otras, por último, que el quijero de la Aljufia pasaba por la heredad ${ }^{38}$.

Son datos que complementan la localización del puente ganadero en Javali ${ }^{39}$, en la inmediatez anterior al azud y próximo al "trastajador» del mismo, en la cabecera de la red de riego para que la curva que la vereda hacía para salvar la huerta no fuese mayor de lo preciso.

En poder de Pedro Ruiz Carrillo y su hermano Sancho Manuel, hijos de Beatriz de Avellaneda estuvieron el patrimonio y con él el puente en los finales del siglo Xv; continuó siendo frágil y de madera y continuaron los requerimientos concejiles para su reconstrucción más sólida para impedir la destrucción de los «...heredamientos que tienen afrontados a los caminos por donde pasan... ${ }^{40}$, hasta que en 1492 uno de estos mandamientos fue dirigido al regidor Pedro Riquelme «...y los otros señores de la puente del açud...." ${ }^{41}$.

5. Cuando el puente ganadero del azud estaba intransitable, los rebaños pasaban por una ruta alternativa extramuros de la Arrixaca occidental, por un puente sobre la Aljufia situado ante la Puerta de la

36 AC 1439, f. 31 rev. (7-XI-1449).

37 AC 1454, f. 38 rev. (16-XI-1454); 1458, f. 28 (14-X-1458); 1465, f. 47 (22-101465) y 1469, f. 41 rev. (16-IX-1469).

${ }_{38}$ AC 1459, f. 27 (11-IX-1459); 1470, f. 78 (9-I-1470); 1472, f. 43 rev. (29-VIII1472) y 59 rev. (3-X-1472); 1473, f. 118 rev. (16-IV-1474); 1477, f. 53 rev. (4-X-1477), 60 rev. (21-X-1477); 1478, f. 107 rev. (7-XII-1478) y 1479, f. 162 rev. (19-II-1480).

39 J. TORRES FONTES, Notas para la bistoria de la ganadería..., p. 143.

40 $A C 1475$, f. 122 rev. (27-IV-1476); 1483, f. 63 rev. (8-XI-1483), f. 116 (23-III1484); 1484, f. 25 (31-VIII-1484); 1486, f. 46 rev. (30-IX-1486); 1487, f. 42 rev (2-X1487) y 67 rev. (11-XII-1487).

${ }^{41}$ AC 1492, f. 143 rev. (1-XII-1492). 
Noguera, reconstruido en $1405^{42}$, cuando la ciudad empezaba a superar las consecuencias de las guerras civiles de los años noventa; la orden de que se construyese de ladrillo y mortero no se pudo cumplir por dificultades económicas que afectaron también al que había de cruzar la acequia de Caravija, y por problemas jurisdiccionales derivados de que la tierra sobre la que había de levantarse había pertenecido al conde de Carrión, a quién se la había comprado Aparicio López de Lobera, que a su vez la vendió al concejo por $214 \mathrm{mrs}$. de moneda vieja, de tal modo que en 1406 se construía precipitadamente uno de madera ${ }^{43}$, para que pudiese ser usado en la inmediata entrada de los ganados de los pastos del campo de Cartagena.

Los ganados bordeaban la ciudad en dirección a los pastos y en la ciudad pagaban los $120 \mathrm{mrs}$. por cada mil cabezas a que estaban obligados como derecho de vereda, o por lo menos las fianzas de que habían de pagar este impuesto y el correspondiente al mantenimiento de las balsas del Campo de Cartagena, fijándose en 1487 la aduana como punto concreto de la recaudación ${ }^{44}$. Este era un factor que explica la abundancia de mesones en las proximidades de la Puerta de Vidrieros, así como la existencia de una gran explanada entre las Puertas de Gil Martínez, la Aduana y el Puente, cruzada a su vez por los ganados ciudadanos que salían por la Puerta de Belchid $^{45}$.

El paso por el puente mayor de la ciudad siempre iba precedido de una licencia global que incluía la condición de que la ciudad cobrase el pontaje correspondiente y los ganados indemnizasen por el daño que pudiesen ocasionar a los cultivos ${ }^{46}$. La sola amenaza de una crecida del río, aunque el puente del azud aún no se hubiese visto afectado, era razón para que se aprobase el desvío por la ciudad, a pesar de que ello era una amenaza para el puente ciudadano y los cultivos; en más de una ocasión se decidió no otorgar más estas licencias, ni siquiera cobrando el concejo el derecho de paso, pero los intereses ganaderos y los de los propietarios del puente del azud eran suficientes y crecientemente importantes para que una ordenanza así impidiese el desplazamiento de los ganados, llegándose en 1485 a que Pedro Carrillo pretendiese cobrar pontazgo a los vecinos de Murcia que utilizasen el puente del azud, si el concejo persistía en su decisión, y el conce-

${ }^{42} A C 1405$, f. 28 rev. (28-VIII-1405).

43 AC 1405, f. 184 (27-IV-1406); 1406, f. 60 rev. (7-VIII-1406), 66 rev. (17-VIII1406), $81(18-\mathrm{IX}-1406)$ y $270(28-5-1407)$.

${ }^{44}$ AC 1487, f. 64 rev. (1-XII-1487) y 1489, f. 188 (30-3-1490).

4s $A C$ 1478, f. 173 (30-IV-1479).

${ }^{46}$ AC 1439, f. 31 (7-11-1439); 1464, f. 97 (19-III-1465); 1465, f. 51 (5-XI-1465); 1483 , f. 63 rev. (8-11-1483) y 1487, f. 105 (21-III-1488). 
jo cedió porque sus vecinos «...de tiempo ynmemorial...» no tenían esa obligación ${ }^{47}$.

Cuando el puente de la ciudad era utilizado con este fin, se hacía un control en la aduana de los que, previa licencia, iban a pasar ${ }^{48}$. Las licencias especiales siempre tienen dos fines definitorios: o se concedían a rebaños muy numerosos o a grandes propietarios muy bien conocidos; en el primer caso estaban, por ejemplo, las otorgadas al vecino de Jumilla Alfonso Herrero, para pasar 550 cabezas en dirección a su villa, o a unos vecinos de Cuenca en 1475 y 1488 para pasar con 400 carneros, que demostraron que habían comprado fuera del término murciano, y a Sancho de Sandoval el mismo año, para el paso de 200 cabezas $^{44}$. Grandes propietarios y a la vez miembros del reducidísimo patriciado local eran los regidores Juan de Cascales, Sancho de Arróniz y Álvaro de Arróniz ${ }^{50}$, el arcediano de Lorca y el deán del cabildo episcopal ${ }^{\text {s1 }}$ y hombres de negocios como los carniceros Fernando de Madrid y Fernando de don Pedro ${ }^{52}$.

6. La siguiente etapa estaba en el cruce de Sangonera, por donde sin duda pasaba la vereda; los testimonios al respecto apuntan a que su trazado era inmediato a las salinas de la rambla del Pino, que los ganados tenían prohibido cruzar, y en cuyas proximidades estaba el «algibe del alcazarejo», del que también se aprovisionaban de agua los ganados ciudadanos, cuyos propietarios contribuían a su limpieza ${ }^{53}$.

El cruce del Sangonera se hacía por el Vadillo Rubio, por donde no había puente asegurado en los finales del siglo XIV, «...los ganados extremeños que vienen al campo de Cartagena et otrosi los ganados de la dicha çibdat, eso mesmo van estremo et vienen et an de pasar por la vereda ques en la dehesa desta dicha çibdat, et an de pasar por el rio de Sangonera et en la vereda por do an de pasar el dicho rio non ay puente por donde puedan pasar el dicho rio, et porque por mengua de la dicha puente los dichos ganados en la dicha pasada del dicho rio fazen grand daño porque riblen aquel...»; esta situación descrita en 1389 se solucionó entonces con la construcción de un puente de piedra, cal y arena, señalizado con un mojón de

${ }^{47}$ AC 1435 , f. 54 rev. (8-II-1436); 1475, f. 83 rev. (3-I-1476); 1484, f. 94 (9-IV$1485) ; 1485$, f. 72 (26-XI-1485) y 75 (3-XII-1485).

${ }^{48}$ AC 1484, f. 11 rev. (6-VII-1484).

49 AC 1474, f. (30-III-1475); 1479, f. 203 (18-IV-1480); 1487, f. 105 (21-III-1488) y 1488 , f. 63 (30-IX-1488).

so $A C 1461$, f. 31 rev. (22-IX-1461); 1467, f. 76 (5-I-1468) y 1494, f. 69 (21-X1494).

${ }^{51} A C 1483$, f. 54 (5-X-1483) y 1489, f. 114 (22-XII-1489).

s2 $A C 1485$, f. 85 rev. (20-I-1486) y 1486, f. 90 (24-II-1487).

${ }_{33}$ AC 1432, f. 39 (6-XII-1432); 1459, f. 40 (20-X-1459); 1477, f. 13 (28-VI-1477); 1484 , f. $114(14-\mathrm{V}-1485)$ y 1498, f. $129(28-\mathrm{V}-1499)$. 
piedra ${ }^{54}$, que en los finales del siglo Xv está perfectamente documentado sobre el Vadillo Rubio, donde a veces se hacían también operaciones de esquileo". No había otro puente ganadero sobre el Sangonera, por cuyo cruce se cobraba un pontaje de $120 \mathrm{mrs}$. por millar de cabezas, que el concejo cedió, con la obligación de su mantenimiento, al regidor Juan de Ayala $^{56}$, el propietario de tierras más importante de las inmediaciones en la segunda mitad del siglo Xv.

En 1476 se rectificó el trazado de la vereda, situando los mojones «... que estan puestos en la vereda de Sangonera al Vadillo Rubio, en par de la herededad de Juan de Ayala..." y, dos años después, la vereda penetraba algo en su herededad llamada del Pino, a la que antes era tangencial; esta heredad de Juan de Ayala era mayor y el concejo prohibía a los ganados detenerse en ella, a instancias del interesado, que sólo permitía su cruce en un máximo de tres días, así como la estancia de los ganados de las carnicerias en los «rigajos» durante cuatro días".

La propiedad de Juan de Ayala no era la única relacionada con la vereda, aunque sí la más afectada por el cruce de los ganados; continuamente los herederos de Sangonera manifestaban su disconformidad con la violación de los mojones por los ganados, porque estas tierras, integradas tradicionalmente en la dehesa concejil, se estaban convirtiendo en explotaciones particulares, en las que el arrendamiento y la venta de «la espiga» de los secanos era la explotación complementaria del cultivo del cereal; por ello la prohibición de que entrasen los ganados en las heredades limítrofes y las frecuentes órdenes de reconstruir los mojones ${ }^{58}$ eran el resultado de la confrontación entre la disminución progresiva de los pastos comunales y la privatización que se estaban operando en ellos.

7. Desde Beniel al Sangonera una vereda a pie de monte se sigue documentalmente, sobre todo en los tramos Beniel Alquerias y ZenetaSangonera, ruta menos activa que la similar de la costera norte entre Santomera y el cerro de San Cristóbal, y afectada por la explotación de la

${ }^{54} A C$ 1389, f. 4 (14-IX-1489).

ss $A C 1477$, f. 81 rev. (19-XII-1477); 1479, f. 210 (2-V-1450) y 1487 f. 51 rev. (27$\mathrm{X}-1487)$. Es posible también la utilización de este puente como paso en el camino de Cartagena, puesto que en 1499 su reconstrucción se financiaba con la renta de las penas de la dehesa, condicionada a que por él pudiesen pasar carretas, $A C$ 1499, f. 97 (7-XII-1499).

${ }^{36}$ AC 1498, f. 92 (5-I-1499) y 98 (9-II-1499).

37 AC 1475, f. 92 rev. (6-II-1476); 1477, f. 81 rev. (19-II-1477) y 1486, f. 60 (21-XI1486).

58 AC 1465, f. 120 rev. (20-V-1466); 1494, f. 88 rev. (9-XII-1494), 100 (3-I-1495) y 1496, f. 52 rev. (24-IX-1496). El amojonamiento de 1487 es el mejor documentado de todos los conocidos, a.c. 1487, f. 136 rev. (5-XII-1487), J. TORES FONTES, Notas para el estudio de la ganadería... 
tierra que se extendía valle abajo del Segura, en la forma de pequeños señoríos. Esta vereda continuaba por la cuenca del Sangonera en dirección a Lorca «... por el paredon ques a la Punta Ynchola...» al pie de la Sierra de Carrascoy"s.

8. Perpendicularmente a esta ruta ganadera la penetración en el Campo de Cartagena se hacía por varias vías complementarias, que de este a oeste eran las siguientes:

El puesto de San Pedro, donde en 1445 almogávares aragoneses se apoderaron de un rebaño de cabras, como tantas veces ocurrió, cuyo inventario permite analizar el escueto bagaje de los pastores, cuyas formas de vida han permanecido casi inmutables a través de los siglos ${ }^{60}$. Era ésta la cañada utilizada para llegar al abrevadero situado en las proximidades de Alquerías, así como la de más fácil entrada desde Aragón, fluctuante en su trazado y sometida a continuas rectificaciones ${ }^{(1)}$.

La siguiente vía transversal hacia occidente era la que penetraba por la rambla del Puntarrón del Puerto de Tiñosa, a la altura de Beniaján, muy poco usada ya en los finales del siglo Xv, pues se obligaba a los ganados a ir por las "costeras" del camino hecho por los herederos de los secanos adyacentes, considerado entonces ya como camino más que como cañada o vereda ${ }^{62}$.

Inmediata a la anterior era la que cruzaba la sierra por Algezares, llegándose a convertir en ruta alternativa de la cañada principal del puerto de Cartagena, cuando el puente del azud estaba inutilizado y los ganados tenían que cruzar por el puente de la ciudad camino del Campo de Cartagena ${ }^{63}$.

Por último, se abría la más importante de todas estas vías transversales, la que siguiendo desde Sangonera llegaba al puerto de Cartagena y siguiendo el curso aproximado de la Rambla del Arraez descendía hacia los pastizales en los que los ganados permanecían el invierno y se sometían a la celebración de dos mestas, que solían ser en Balsapintada la de otoño y en la Torre del Arraez la de primavera ${ }^{64}$, antes de iniciar el retorno a sus tierras de origen por los mismos caminos que habían seguido en su venida.

s9 AC 1469, f. 113 rev. (19-V-1470); 1487, f. 129 rev. (17-V-1488); 1495, f. 39 (3$\mathrm{X}-1495)$ y 1503 , f. 120 rev. (27-II-1504).

60 13 asnos, 4 zamarras, 1 caldero, las "amasaderas" y un "tornillo" con mantas y cedras (las alforjas de pellejo de los pastores), a.c. 1445, f. 21 rev. (17-VIII-1445).

${ }^{61} A C 1487$, f. $128(13-V-1488)$ y 1489, f. 126 (7-I-1490). En 1478 se daba licencia a los herederos afectados por la salida de los ganados de la vereda a degollar las reses incautadas, como penas debidas, a.c. 1477, f. 116 rev. (13-III-1478), 119 rev. (27-III-1478) y 121 (31-III-1478).

${ }^{62} A C$ 1498, f. 122 (4-V-1499). Ginés Pedriñán se obligaba a mantener el camino en 1485, a cambio de poder arrendar la espiga, a.c. 1484, f. 117 (28-V-1485).

63 AC 1415 , f. 172 rev. (9-V-1416).

${ }^{64}$ M. ${ }^{2}$ Ll. Martínez Carrillo, Revolución urbana... p. 259. 


\section{RÉSUMÉ}

La cartographie concernant les routes suivies par les troupeaux dans l'ancien royaume de Murcie fait montre de grandes lacunes et d'un manque total de précision; le fait est dû au haut degré d'autonomie juricdictionnel qui caractérisait l'administration des pâturages et leurs voies de communication dans cette région. Le chemin de Cuenca était la principale route de Castille qui pénétrait en territoire murcien, d'où il se prolongeait par un réseau de sentiers vertébrés à partir du "sentier principal", ce dernier établissait la connexion entre les terres de Cuenca et la plaine de Cartagène à travers Abanilla, Santomera, les collines de San Cristobal, le Pont de l'Azud et le Port de Cartagène.

\section{SUMMARY}

The cartography available about the roads used by the cattle presents an important lacune and is not very precise as far as the Reign of Murcia is concerned. The clue lies in the fact that pastures and communication roads in Murcia depended on a government strongly characterised by a high degree of jurisdictional autonomy. Cuenca's cattle track was the main Castillan way that penetrated in Murcian territory, where a network of paths vertebrated themself around a main path that connected the region of Cuenca with the fields of Cartagena through Abanilla, Santomera, the hills of San Cristobal, the Azud bridge and Cartagena's harbour. 